\title{
A Clinical Study on Treatment of Facial Freckles with Intense Pulsed Light
}

\author{
Yan Xiao \\ Dipartment of Dermatology,Southwest Hospital,Third Military Medical University,Chongqing 400038,China
}

\begin{abstract}
Purpose: To explore the clinical effect of intense pulsed light on freckles. Methods: A total of 102 patients with facial freckles treated in our hospital between November 2014 and May 2017 were taken as the subjects of this study. The patients, after being confirmed with facial freckles, were treated with M22 Photorejuvenation, and evaluated at the end of the treatment in terms of therapeutic effect, adverse reactions, changes of indicators before and after treatment as well as relapse. Results: In terms of treatment effect, there were 46 patients $(45.10 \%)$ above expectation, 50 patients $(49.02 \%)$ up to expectation and 6 patients (5.88\%) below the standard, with a total effective rate of $94.12 \%$. In terms of adverse reactions, there were 8 patients with temporary facial flushing, 4 patients with mild edema and 3 patients with burning sensation, with a probability of $14.71 \%$. In terms of indicator changes before and after treatment, the skin elasticity and skin moisture of each part of the patient's face were improved, with the skin elasticity of the patient's forehead and lower jaw up by $8.9 \%$ and $8 \%$, respectively, and the skin moisture of the patient's left cheek up by $25.7 \%$, which was very obvious. In addition, the proportion of melanin and skin oil of the patients were significantly reduced, with the melanin proportion of the left cheek down by $30.1 \%$ and the overall skin oil proportion of the face down by about $1 \%$. At the end of the treatment, 5 patients had freckle recurrence, with a recurrence rate of $4.90 \%$, which was statistically significant $(\mathrm{P}<0.05)$. Discussion: The intense pulsed light is an effective tool in the treatment of facial freckles. Despite occasional adverse reactions, multiple indicators of various parts of the patient's face have been significantly improved, with a low probability of later recurrence, making it worthy of clinical promotion.
\end{abstract}

\section{Introduction}

Facial freckles not only affect the patient's appearance, but may also cause other skin diseases under certain circumstances, undermining the patient's personal image and life quality. Therefore, the study took 102 patients with facial freckles who had received treatment in our hospital as the subjects of the research to observe the efficacy of M22 Photorejuvenation against facial freckles. The procedures were as follows.

\section{Research Information}

\subsection{General Information}

A total of 102 patients with facial freckles treated in our hospital between November 2014 and May 2017 were taken as the subjects of this study. The patients were confirmed with facial freckles, and the hospital sought the consent of all patients and their families. Among all the patients, there were 10 male patients and 92 female patients, aging from 20 to 41 years old with an average age of $33.9 \pm 3.5$ years old. In terms of freckle distribution, 25 patients had freckles in the zygomatic region, 49 in the buccal region, 26 in the nasal region, and 2 in both the nasal and buccal regions. In terms of the color of the freckles, 40 patients had lighter freckles while the other patients were darker. All the patients were non-allergic, with freckles ranging from 1 to $4 \mathrm{~mm}$ in size, and none of the patients had been treated with drugs that had an impact on the treatment of freckles for within a month. The general information of the patients was not significant $(\mathrm{P}>0.05)$.

\subsection{Research methods}

\subsubsection{Instrument selection}

In this study, M22 Photorejuvenation was used to treat patients, with an output wavelength of $400 \mathrm{~nm}-1200 \mathrm{~nm}$ (blue) and 500nm-1200nm (yellow) and a spot area of $47 \mathrm{~mm} \times 21 \mathrm{~mm}$ and $20 \mathrm{mmX} 10 \mathrm{~mm}$. In terms of pulse, the pulse width of the M22 Photorejuvenation is set between $25 \mathrm{~nm}-55 \mathrm{~nm}$ and the working interval stands at 2-6 seconds. Other parameters can be set according to the actual needs of patients.

\subsubsection{Treatment}

All patients were treated with M22 Photorejuvenation for 
facial freckles. As part of the preparation before treatment, the patient should first be kept in an appropriate position to ensure that he/she is in the state of supine. The patient's face was cleaned to fully expose the freckles so that doctors could determine the location of the freckles. Both doctors and patients should measure to protect their eyes against the strong light emitted by the instrument. A picture of the patient's face was taken before treatment to facilitate postoperative comparison. Before treating the patient with the M22 Photorejuvenation, cold gel was applied to the head or local area of the instrument, and then light spots were emitted, with 3 or 4 light spots at a time. The cold gel was reapplied before each emission until the last emission. Then the cold gel was removed and the face was cleaned. Finally, in case of facial swelling that would affect the observation of the freckles, appropriate regulation of energy density was required to avoid pigmentation, facial edema and other adverse reactions. Ice was applied to the area receiving treatment with a duration of no more than 30 minutes. Doctors and nurses should always remind the patients of sun protection, and give patients vitamin $\mathrm{C}$, vitamin $\mathrm{E}$ as well as endothelin antagonists as an adjuvant therapy. All patients received 3 courses of treatment, each course with 3-5 times of treatment. After the treatment, the effect of treatment, adverse reactions, changes in indicators before and after treatment, and recurrence were investigated.

\subsection{Evaluation Standard}

Our hospital divided the treatment efficacy into three categories: distinct, effective and ineffective. Patients whose pigmentation was reduced by more than $50 \%$ were rated as distinct. Patients were rated as effective if their pigmentation was reduced by between $25 \%$ and $50 \%$. Patients with less than a $25 \%$ reduction in pigmentation were rated as ineffective.

\subsection{Statistics}

SPSS 22.0 was used to analyze the data, where $\mathrm{X} \pm \mathrm{S}$ represented the counting data, and X2 for the test of the counting data. The data in the study were examined by $\mathrm{T}$ test, and those whose $\mathrm{P}<0.05$ was considered statistically significant.

\section{Result}

\subsection{Effects of treatment}

Our hospital conducted a detailed examination on the treatment effect of the patients, among which 46 patients achieved obvious effects, accounting for $45.10 \%$ of the total; 50 patients had effective treatment, accounting for $49.02 \%$. Only 6 patients had poor or ineffective treatment. The overall effective rate was as high as $94.12 \%$, indicating statistical significance $(\mathrm{P}<0.05)$.
Table 1 Treatment Effect of Patients [n (\%)]

\begin{tabular}{|c|c|c|c|c|}
\hline $\begin{array}{c}\text { Case } \\
\text { Numb } \\
\text { er }\end{array}$ & $\begin{array}{c}\text { Obviously } \\
\text { Effective }\end{array}$ & Effective & $\begin{array}{c}\text { Ineffectiv } \\
\mathrm{e}\end{array}$ & $\begin{array}{c}\text { Effective } \\
\text { Cases in Total }\end{array}$ \\
\hline 102 & $46(45.10)$ & $50(49.02)$ & $6(5.88)$ & $101(94.12)$ \\
\hline
\end{tabular}

\subsection{Adverse reactions among patients}

In this study, a total of 15 patients had adverse reactions, including 8 patients with temporary facial flushing, 4 patients with mild edema, and 3 patients with burning pain. The incidence of adverse reactions was $14.71 \%$, showing statistical significance $(\mathrm{P}<0.05)$.

Table 2 Adverse Reactions among Patients [n (\%)]

\begin{tabular}{|c|c|c|c|c|}
\hline $\begin{array}{c}\text { Case } \\
\text { Numb } \\
\text { er }\end{array}$ & $\begin{array}{c}\text { Temporary } \\
\text { Facial } \\
\text { Flushing }\end{array}$ & $\begin{array}{c}\text { Mild } \\
\text { Edema }\end{array}$ & $\begin{array}{c}\text { Burning } \\
\text { Pain }\end{array}$ & $\begin{array}{c}\text { Cases of } \\
\text { Adverse } \\
\text { Reactions }\end{array}$ \\
\hline 102 & $8(7.84)$ & $4(3.92)$ & $3(2.94)$ & $15(14.71)$ \\
\hline
\end{tabular}

\subsection{Changes of indicators before and after treatment}

The hospital carried out a comprehensive examination of indicators including the skin elasticity, melanin level, skin moisture and skin oil level of the patients before and after treatment by detecting body parts such as the forehead, left cheek, right cheek, nasal tip and lower jaw. It was found that the skin elasticity and skin moisture of all the tested parts of the patients were significantly improved while the level of skin melanin and skin oil decreased, among which improvement in the skin elasticity of the forehead and the lower jaw were the most significant, with an increase of $8.9 \%$ and $8.0 \%$, respectively. The skin moisture of the patient's left cheek increased the most by $25.7 \%$, while the melanin level of the patient's left cheek decreased significantly by $30.1 \%$. In addition, there was a slight decrease in the skin oil level. The data were statistically significant $(\mathrm{P}<0.05)$.

Table 3 Changes of Indicators Before and After Treatment (\%)

\begin{tabular}{|c|c|c|c|c|}
\hline $\begin{array}{c}\text { Body } \\
\text { Part }\end{array}$ & $\begin{array}{c}\text { Skin } \\
\text { Elasticity }\end{array}$ & $\begin{array}{c}\text { Melanin } \\
\text { Level }\end{array}$ & $\begin{array}{c}\text { Skin } \\
\text { Moisture }\end{array}$ & $\begin{array}{c}\text { Skin Oil } \\
\text { Level }\end{array}$ \\
\hline $\begin{array}{c}\text { Forehe } \\
\text { ad }\end{array}$ & +8.9 & -17.9 & +10.8 & -0.15 \\
\hline $\begin{array}{c}\text { Left } \\
\text { Cheek }\end{array}$ & +2.8 & -30.1 & +25.7 & -0.11 \\
\hline $\begin{array}{c}\text { Right } \\
\text { Cheek }\end{array}$ & +1.7 & -23.6 & +10.1 & -0.08 \\
\hline $\begin{array}{c}\text { Nasal } \\
\text { Tip }\end{array}$ & +1.6 & -2.0 & +3.0 & -0.17 \\
\hline $\begin{array}{c}\text { Lower } \\
\text { Jaw }\end{array}$ & +8.0 & -6.1 & +3.9 & -0.15 \\
\hline
\end{tabular}

\subsection{Recurrence after treatment}

After the treatment, 5 patients experienced freckle recurrence, that is, the recurrence rate was $4.90 \%$. 


\section{Discussion}

There are many ways to treat freckles in clinical practice, including laser and skin peeling treatment. However, these traditional treatment approaches could lead to severe pigmentation, leaving obvious scars in the patient's face and a lot of pain and adverse reactions during the treatment. In this study, the M22 Photorejuvenation was used to remove freckles by changing the temperature of patients' facial skin in different parts and decompose the pigment diagram and pigment cells based on the intense pulse light. In this study, the overall effective rate of treatment reached $94.12 \%$, and the incidence of adverse reactions was $14.71 \%$. All patients were significantly improved in terms of each indicator after treatment, with a low level of injury to the patients' faces and a recurrence rate of only $4.90 \%$. In general, the treatment of facial freckles with intense pulsed light has a significantly better effect than traditional treatment methods, with a lower incidence of adverse reactions, and thus it is worthy of promotion.

\section{References}

1. Lian Xiyan, Ding Yan, Bo Dan. Treatment of Facial Freckles by Intense Pulse Light [J]. Chinese Journal of Aesthetic and Plastic Surgery, 2004, 15 (01): 23-25.

2. Liu Hongli. Clinical Studies of 40 Cases of Facial Freckles Treatment by Intense Pulse Light [J]. China Medical Abstract of Dermatology, 2015 (5): 95-95.

3. Zhang Fang. Clinical Observation of Facial Freckles Treatment by Intense Pulse Light [J]. China Medical Cosmetology, 2015, 5 (06): 62-63.

4. Zhao Junwen. Clinical Analysis of Facial Freckles Treatment by Intense Pulse Light [J]. World Latest Medicine Information: Electronic Version, 2013 (16): 89-89. 